\title{
'Nuclear' \\ is not the \\ question
}

\author{
Whether we should expand the use of nuclear energy is not the issue. Developing \\ next-generation nuclear technology as part of a clean-energy portfolio is.
}

In this issue we take a closer look at recent developments in nuclear energy. Obviously, this remains a very sensitive topic to many. On the one hand, nuclear power is a reliable source of energy that uses cheap fuel (at least at present) and therefore holds the promise of stable energy prices, even when taking into account the costs of construction as well as decommissioning. It is also regarded as a technology with comparatively low carbon dioxide emissions. On the other hand, many people fear that the risks of nuclear accidents outweigh the benefits.

For these reasons the commissioning of new nuclear power plants has been halted in a number of countries and research in nuclear technology has been reduced significantly. However, in the face of significant increases in fossil fuel prices as well as insatiable demands for cheap energy in rapidly developing countries, nuclear power has seen a significant revival. According to International Atomic Energy Agency figures, at present there are 439 operating nuclear reactors worldwide, with 35 under construction.

The renewed interest in nuclear energy has been met with criticism, but the significant improvements in nuclear safety of recent years need to be acknowledged. Some of these initiatives are detailed in our interview on page 686 with Tomihiro Taniguchi, Deputy Director General at the IAEA with responsibility for nuclear safety and security. Obviously, an important issue in nuclear safety remains the human factor, but even this threat is minimized by the development of passively safe nuclear reactors, where a complete failure of all systems would lead to an automatic slow-down of the nuclear reaction.

At the same time, further improvements in nuclear technology

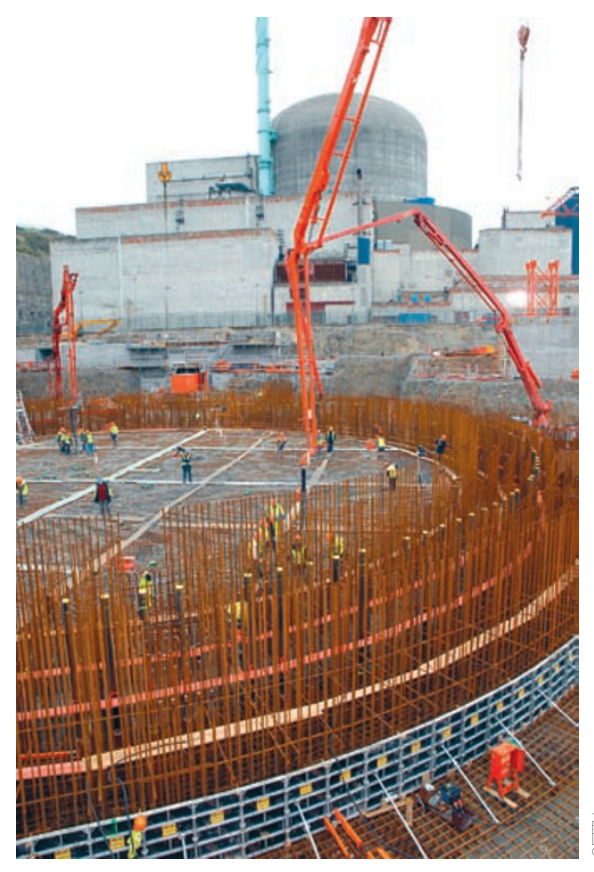

Construction of a new nuclear reactor in Flamanville, France.

can be expected from generation IV reactors that are currently under development. The high operation temperatures envisioned for these reactors are crucial to be able to use the fuel more efficiently, and at the same time allow the production of hydrogen using the process heat from the reactors. Indeed, in his Commentary on page 680 David Hill, Deputy Laboratory Director for Science and Technology at Idaho National Laboratory, argues that a broader use of nuclear power beyond electricity is essential to realize its full potential. Last but not least, nextgeneration reactor designs also help to mitigate the challenge of long-term storage of spent fuel as they allow the use of more recycled fuel. However, these high operation temperatures also create challenges in materials research, some of which are highlighted in a Commentary by Robin Grimes, Rudy Konings and Lyndon Edwards on page 683.

Will these advances in technology signify a landslide shift towards a greater use of nuclear power? Probably not in the near future. It will be impossible for the construction of new power plants to keep up with the overall increase in energy demand. Unfortunately, this gap in energy production is filled mostly with coal, particularly in China and India. In 2007, their nuclear share in electricity generation was only $1.9 \%$ and $2.5 \%$, respectively, compared with $19.4 \%$ in the United States and $76.9 \%$ in France. Therefore, it is crucial to develop green technologies to mitigate the effects of these fossil energy sources.

Although the global share of nuclear power in primary energy is only $6 \%$ (16\% for electricity), nuclear power has to have an increasingly important role in our energy supply. In particular, nuclear energy offers a constant base load that is capable of supporting the crucial boost in the more volatile renewable technologies such as wind, solar and tidal power.

Nuclear energy is here to stay, and its use should and will continue to increase. As fossil fuel prices rise, the benefits offered by nuclear technology will become more evident to the average consumer, and the political pressure to intensify the development of nuclear technology will increase. Given the long lead times for the construction of new nuclear power plants, we cannot afford to wait and see. More intense research efforts towards the advance of nuclear technology are needed, now. 